\title{
Calcineurin Inhibitor Nephrotoxicity: A Review and Perspective of the Evidence
}

\author{
Naim Issa Aleksandra Kukla Hassan N. Ibrahim \\ Division of Renal Diseases and Hypertension, University of Minnesota, Minneapolis, Minn., USA
}

\author{
Key Words \\ Graft loss · Calcineurin inhibitors · Nephrotoxicity $\cdot$ Chronic \\ kidney disease $\cdot$ Kidney transplantation
}

\begin{abstract}
Background: There is no doubt that acute calcineurin inhibitor (CNI) nephrotoxicity exists; however, chronic CNI nephrotoxicity is questionable at best. Methods: We reviewed the literature to identify original articles related to the use of CNIs in renal and nonrenal solid organ transplantation in order to examine the available evidence about their chronic nephrotoxicity and contribution to graft failure. Results: Early clinical experience and animal studies support the evidence of $\mathrm{CNI}$ nephrotoxicity. These findings evolved into the dogma that CNI nephrotoxicity is the major cause of late renal allograft failure. However, in transplanted kidneys the specific role of chronic CNI nephrotoxicity has been questioned. The emerging literature clearly highlights the lack of solid evidence for the role of CNIs as the sole and major injurious agents that cause chronic renal dysfunction and subsequent graft failure. Most of the evidence available to date is against complete $\mathrm{CNI}$ avoidance, and minimization appears to be a more viable strategy. It is becoming increasingly clear that the typical pathological lesions linked to chronic CNI use are highly nonspecific, and most of the chronic changes that have been attributed to chronic CNI nephrotoxicity are the
\end{abstract}

consequences of previously unrecognized immunologic injuries. One needs to keep in mind that the potential risk of side effects of CNI use should be balanced against the risk of rejection. Conclusions: More research should focus on addressing the true causes of chronic graft dysfunction rather than focusing on the overexaggerated contribution of CNIs to late graft loss.

Copyright $\odot 2013$ S. Karger AG, Basel

\section{Introduction}

It has become cliché to state that kidney transplantation has achieved excellent short-term outcomes, but long-term outcomes have not improved since the introduction of cyclosporine (CsA) in 1983 [1]. Chronic calcineurin inhibitor (CNI) nephrotoxicity has been incriminated in the lack of improvement in long-term kidney allograft survival as it has been described to be 'universally' present at 10 years, even in grafts with excellent function [2]. While there is no doubt that acute CNI nephrotoxicity exists, it has been postulated for the last three decades that chronic CNI use not only contributes to late allograft loss, but may also be the major cause of chronic renal allograft damage characterized by progressive and irreversible deterioration of renal function associated with interstitial fibrosis, tubular atrophy, arteriolar

\section{KARGER}

E-Mail karger@karger.com

www.karger.com/ajn
(C) 2013 S. Karger AG, Basel

0250-8095/13/0376-0602\$38.00/0
Hassan N. Ibrahim, MD, MS

Division of Renal Diseases and Hypertension, Department of Medicine University of Minnesota

717 Delaware Street, S.E., Suite 349, Minneapolis, MN 55414 (USA)

E-Mailibrah007@umn.edu 
hyalinosis, and glomerulosclerosis. Several theories about the mechanisms leading to chronic CNI nephrotoxicity including molecular mechanisms, pharmacokinetics, therapeutic drug monitoring, and pharmacogenetics have been carried out. In this article, we review the molecular mechanisms, the clinical and histological aspects of chronic CNI nephrotoxicity, and different CNI-sparing protocols, as well as examine the recent evidence regarding chronic CNI nephrotoxicity and its role in renal dysfunction and allograft loss.

\section{Acute versus Chronic CNI Nephrotoxicity}

The CNIs in current clinical use include CsA and tacrolimus (TAC). While CsA and TAC differ in their molecular structure and intracellular binding characteristics, their immunosuppressive properties result from inhibition of a calcium- and calmodulin-dependent phosphatase protein or calcineurin. CsA binds to cyclophilin, while TAC binds to FKBP12 (originally designated FK506) [3-5]. Binding of CsA-cyclophilin and TACFKBP12 to calcineurin inhibits the phosphatase activity of calcineurin and thereby suppresses the transcription of IL-2 by impairing the translocation of the nuclear factor of activated T cells (NFAT) which regulates IL-2 transcription and thus $\mathrm{T}$ cell activation [6-10]. Since the inhibition of the calcineurin-NFAT pathway by CNIs is not specific to immune cells, it is evident that CNIs cause toxic changes in addition to immunosuppressive effects [11, 12]. Furthermore, the potential nephrotoxic effects of CNIs stem from the evidence that the molecular effects of CNIs are not limited to NFAT-dependent mechanisms.

The choice between TAC and CsA is largely based on the preferences of the transplant centers or treating physician, as well as the side effect profiles of each medication that are individually tailored to the recipient. TAC is currently the main CNI in use in the United States, in combination with mycophenolate mofetil (MMF) with or without steroids. The combination of TAC and MMF has been associated with lower rates of acute rejection (AR) episodes [13]. Many of the side effects of the CNIs surrounding CNI nephrotoxicity stem from the time when CsA was in early development and later with TAC use. CNIs induce vasoconstriction of the afferent arteriole by causing an imbalance between vasoconstrictor agents such as endothelin, thromboxane and activation of the renin-angiotensin system and decrease of vasodilator factors like prostaglandin $\mathrm{E}_{2}$, prostacyclin, and nitric oxide [14-19]. The arteriolar vasoconstriction induces an acute reversible impairment of renal function and also acute reversible tubular dysfunction. The inhibition of the calcineurin-NFAT signaling by CNIs induces COX-2 inhibition which leads to renal vasoconstriction and also a reduced glomerular filtration rate (GFR) [20, 21]. This vasoconstriction is dose-dependent and is reversible [22, 23]. Histologically, acute CNI hemodynamic effects are associated with any morphologic lesions. It is worth noting that chronic CNI nephrotoxicity is only partly elucidated.

\section{CNI Pharmacokinetics and Pharmacogenetics: How Tight Is the Link to Nephrotoxicity?}

It was clear from the early works that there is an association between CNI dose and levels and nephrotoxic effects. In fact, since CNIs have a narrow therapeutic window, great care should be given to maintain a balance between efficacy and toxicity, which is typically achieved by keeping the drug levels within the target ranges [24]. CNIs exhibit high inter- and intraindividual pharmacokinetic variability due to their inherent high variability in absorption, distribution, metabolism, and elimination. Their intestinal absorption is variable and influenced by food intake, ethnicity, and diarrhea. CNIs are mainly distributed in erythrocytes, but are also bound to plasma proteins. They are mainly metabolized in the liver by the cytochrome P450 3A isozymes and their metabolites are mainly eliminated in the bile, with less than $5 \%$ excreted in the urine. CNI pharmacokinetics are largely influenced by other drugs (e.g. macrolide antibiotics, calcium channel blockers, antifungals, etc.) as well as genetic polymorphisms in CYP3A5 enzymes (discussed below). Moreover, certain conditions such as diarrhea affect the activity of those enzymes and influence the levels of CNIs, particularly TAC [25]. In order to prevent their side effects, the CNI dose is typically adjusted in the context of diarrhea.

Trough CNI concentrations are routinely checked in order to adjust their doses to avoid nephrotoxicity. TAC trough concentrations correlate better than CsA with the area under the time-concentration curve (AUC 0-12 h). Monitoring of the 2-hour postdose CsA concentration was found to correlate better than the trough CNI concentration with the total drug exposure [26], but in clinical practice 2-hour postdose CsA concentration monitoring is more cumbersome [27].

The evidence of association of chronic nephrotoxicity lesions with higher systemic exposure to CNIs is not 
strong [28]. In fact, more evidence is emerging that the exposure to low CNI levels is associated with higher chronic histological damage $[29,30]$. In randomized trials [31-33], the high-CNI exposure group did not have significantly lower graft function, which refutes the chronic nephrotoxic effects. The role of drug transporters and drug metabolizing enzymes in causing interindividual variability in CNI pharmacokinetics has recently been reviewed by Hesselink et al. [34]. The drug transporter adenosine triphosphate-binding cassette protein B1 (ABCB1), which is responsible for transporting drugs from the cytoplasm to the cell surface and then into the extracellular space, is found most prominently in the brush border of proximal tubular epithelial cells of human kidneys. It was shown that the ABCB1 genotype and expression of $\mathrm{P}$-glycoprotein in renal tubular epithelial cells determine the susceptibility to chronic tubulointerstitial damage of transplanted kidneys [35]. ABCB1 is upregulated in the setting of CsA exposure, which likely serves as a protective mechanism against CsA exposure. On the other hand, lower $\mathrm{ABCB} 1$ expression has been shown to be a risk factor for chronic histologic changes in kidney transplant patients treated with CNIs, and the reduced intrarenal expression of CYP3A5 in renal biopsies may be a risk factor for nephrotoxicity in patients treated with CNIs $[35,36]$. Conversely, other studies have failed to demonstrate a correlation between allograft survival and the $\mathrm{ABCB} 1$ genotype or the association of the CYP3A5 genotype and CNI-mediated nephrotoxicity [37, 38]. Overall, the available data on this subject remain conflicting.

There are many local renal factors that may play a role in chronic CNI toxicity, such as genetic polymorphisms in CYP3A4/5, older kidney age, and salt depletion [39]. More recently, Djamali et al. [40] studied the potential CNI-induced fibrogenic activity of Nox 2 and showed that Nox2 is involved in the pathogenesis of CNI-induced renal injury. Nox2 expression was increased in human and animal models of chronic CsA-induced fibrosis. They showed that the inhibition of Nox 2 activity was associated with reduced CsA-induced fibrosis. Whether those findings can be translated into daily clinical practice is still unclear.

\section{CNI Use and Native Kidney Dysfunction in Extrarenal Solid Organ Transplantation}

Renal dysfunction remains a major challenge to nonrenal solid organ transplant outcomes as it is associated with increased morbidity and mortality. While there is no doubt that CNI use may contribute somehow to native kidney dysfunction after solid organ transplantation, an examination of the available literature found solid evidence linking kidney dysfunction to chronic use of CNIs. It is worth noting that there are substantial differences between renal allograft transplant and nonrenal solid organ transplantation, mainly the alloimmune response to the 'non-self' renal grafts. Therefore, in non-renal solid organ transplantation acute rejection phenomena that are key determinants of renal function are absent. Moreover, it has been suggested that CsA stimulates sympathetic nerve activity in native kidneys, which plays a role in the acute nephrotoxic effects of CsA by increasing renal vascular resistance and thereby causing an acute decline of the GFR [41]. Transplanted kidneys lack sympathetic innervation, so the potentiation of those nephrotoxic effects by CNIs is not observed through sympathetic upregulation in renal allografts [42]. In nonrenal solid organ transplantation, the context is not complicated by rejection and alloimmune phenomena. However, because no routine kidney biopsies are performed in nonrenal transplant recipients, not much data are available on the evolution of histological CNI-related nephrotoxicity. There are several risk factors for renal dysfunction in the pre-, peri-, and posttransplant periods (i.e. perioperative acute tubular necrosis, hypotensive episodes, diuresis, administration of nephrotoxins such as intravenous contrast agents, sepsis, etc.) that influence long-term posttransplant renal function.

The initial report linking CNIs to renal damage was by Myers et al. [43] who described that long-term CsA use in heart transplant recipients may lead to irreversible renal dysfunction. Of note, the targeted trough CsA levels in this study were very high in the range of 300-350 ng/ $\mathrm{ml}$. Ojo et al. [44] studied the cumulative incidence of chronic kidney disease (CKD) in a large cohort of different solid organ transplants, and the use of CNIs was associated with increased relative risk for kidney dysfunction but was not found to be a risk factor for CKD in a multivariate analysis.

In liver transplantation, no differences were found in renal function or the incidence of nephrotoxicity between high- and low-level CsA groups [45]. In a randomized trial on CNI minimization in liver transplantation the delayed introduction of low-dose TAC, in combination with daclizumab and MMF, appeared to preserve early renal function with a low incidence of $A R$, however those beneficial effects had dissipated by 1 year posttransplantation [46]. McGuire et al. [47] performed protocol kidney biopsies in 30 patients with hepatitis $\mathrm{C}$ and normal 
kidney function who underwent orthotopic liver transplantation. More than $80 \%$ of those patients had evidence of silent immune-complex glomerulonephritis.

It is undoubtable that CNIs play some role in potentiating acute and chronic kidney injury during and after solid organ transplantation, but it remains unknown what is their true contribution as the main injurious agents in causing CKD [48]. Many other previous and subsequent studies in various solid organ transplantations reported that CNI use was not the only factor causing CKD and in fact there was a variable contribution of CNIs in such kidney injury [49-52]. One should note that the differences that could explain the disparity in the role of CNIs in the incidence of CKD in those studies is that there are wide array of $\mathrm{CNI}$ level targets that clinicians maintain in different solid organ transplants, which may add more challenge to interpreting those studies and the true contribution of CNIs to renal dysfunction. On the other hand, one would argue that the most compelling evidence for nephrotoxic effects of CNIs derives from the published data about CsA use in different autoimmune diseases such as psoriasis and uveitis [53-55]. While there is no doubt that CNIs would have somehow contributed to CKD development in this population, the same limitations described in transplant population studies apply to those studies, including the absence of histology in most of the cases, absence of drug level targets, and other unaccounted for risk factors for CKD development and progression.

\section{No Histological Lesions Are Specific for CNI Nephrotoxicity!}

The exact contribution of CNIs alone to the development of chronic pathological lesions in kidney allograft and their role as predominant contributors to the failure of the allograft over time have been evaluated in numerous studies.

The early literature suggesting that chronic CNI nephrotoxicity is a major cause for renal allograft failure was based on association studies between histological lesions that were considered specific for CNI nephrotoxicity (such as striped interstitial fibrosis, arteriolar hyalinosis, tubular atrophy, and glomerulosclerosis) and renal allograft function and outcomes. The association between these lesions and use of CNIs was first described by Mihatsch et al. [56] who observed arteriolar hyalinosis in renal transplant recipients treated with CsA. Renal biopsies were obtained from healthy kidney donors and from kidney transplant recipients receiving CsA, and showed that arteriolar hyalinosis was present in CsA-treated recipients but not in young and healthy kidney donors. These findings increased the probability of association of arteriolar hyalinosis with CNI use. Of note, the CsA trough levels in this study were very high $(1,000-1,500$ $\mathrm{ng} / \mathrm{ml}$ ) compared to the current immunosuppression era. However, it is now well known that other disease processes can cause arteriolar hyalinosis as well.

Nankivell et al. [2] attributed the chronic changes in renal allografts (such as high-grade arteriolar hyalinosis with luminal narrowing, increasing glomerulosclerosis, and tubulointerstitial damage) based on protocol biopsies to the chronic use of CNIs. The authors also reported that the prevalence of those lesions continue to evolve over time and are almost universal at 10 years posttransplant, even in allografts with excellent early histologic findings. However, their study lacked a control group and the biopsies were from a cohort of 120 recipients with diabetes mellitus type 1, all but one of whom had received simultaneous pancreas-kidney transplants. Furthermore, all were bladder-drained pancreas transplant recipients who are prone to interstitial fibrosis and tubular atrophy of the kidney allografts based on urinary reflux, rendering their results hard to apply and generalize to kidney transplantalone recipients. What is intriguing in this study is that the 10 -year death-censored graft survival was $95.2 \%$ with the use of CNIs. Chronic CNI-related renal damage also does not hold true in later studies.

Another major issue in this study is that an association was linked to causation in the context of an observational trial in simultaneous kidney pancreas transplant recipients. The same group in a subsequent study in euglycemic kidney-pancreas transplant recipients showed that subclinical rejection was more common in CsA- and azathioprine-treated patients compared to those on CsA and MMF, and that interstitial fibrosis and tubular atrophy and vascular lesions were more prevalent in these patients, suggesting the limitation of immune-mediated injury plays a role in causing interstitial fibrosis and tubular atrophy [57]. In a study by Mazur et al. [58], bladder-drained pancreas transplant alone resulted in a decline in native renal function in the majority of patients regardless of the pretransplant GFR, highlighting that several factors play a role, and perhaps not only CNI use, in causing renal dysfunction in bladder-drained pancreata.

Naesens et al. [29] showed that AR episodes and exposure to low TAC levels were independent risk factors for the development of chronic pathological lesions in 
allografts at 1 year posttransplantation based on protocol biopsies, suggesting that rejection and alloimmunemediated mechanisms remain important in the early progression of chronic renal allograft pathology. Snanoudj et al. [59] retrospectively compared 48 kidney transplant recipients who received CsA to 93 kidney recipients who did not have any exposure to CNIs. All patients in this study underwent protocol biopsies at 3 months, 2 years, and 10 years after transplantation. They reported that the histological lesions commonly attributed to chronic 'CsA nephrotoxicity' (such as glomerulosclerosis, interstitial fibrosis, tubular atrophy, arteriolar hyalinosis, and fibrointimal thickening) were not sufficiently specific to definitively diagnose CNI nephrotoxicity. While Snanoudj et al. found that arteriolar hyalinosis, considered to be the most specific pathological lesion of CNI nephrotoxicity, was more frequent and more severe in the CNI group (92\% of patients at 10 years); the same lesions were present in $65 \%$ of patients who never had any exposure to CNIs. This adds more to the body of evidence that there are truly no specific histological lesions for chronic CNI toxicity [60]. It is also worth noting that tubulointerstitial injury in renal allografts occurs early on from ischemia-reperfusion injury, and subsequently from acute cellular rejection or subacute persistent rejection, as well as from BK virus infection that is often accompanied by a destructive mononuclear infiltrate generating acute tubulointerstitial nephritis followed by chronic interstitial fibrosis [61] that could have been missed and attributed to CNIs in the past. A replicating virus forms intranuclear inclusions and enlarged nuclear chromatin within renal tubular cells (confirmed by SV40T viral immune staining), which is accompanied by degeneration, apoptosis, and cellular detachment with mononuclear inflammation thereby causing allograft failure [62-64].

Another concern for the histologic diagnosis of $\mathrm{CNI}$ nephrotoxicity is the poor reproducibility of the histologic grading of the lesions. None of the studies looking at CNI nephrotoxicity at a histologic level measured intra- and interobserver agreement. Despite the evolving refinement of the histologic scoring according to the Banff pathology classification of renal allografts, it remains incredibly difficult to account for inter- and intraobserver variability. Thus, even attributive classification could be flawed based on this, both in the same study and when comparing different studies in different transplant centers.

\section{CNI-Sparing Protocols}

Many clinical trials have been carried out by looking at minimization, avoidance, or complete elimination of CNIs in order to address the issue of chronic CNI nephrotoxicity and minimize it (table 1). The earlier reports of CsA or TAC use along with sirolimus (SRL) in order to minimize CNIs showed a decrease in AR incidence compared to a regimen of CsA, azathioprine, and glucocorticoids [65]. Conversely, later reports showed that the use of SRL in combination with CNIs is associated with inferior graft survival and renal dysfunction compared with CsA or TAC with MMF and corticosteroids [66-70]. For that reason the use of CNIs combined with SRL is generally considered in patients on an individualized basis due to issues of aforementioned CNI toxicity potentiation and overall inferior graft outcomes.

\section{CNI Avoidance and Minimization Protocols}

$\mathrm{CNI}$ avoidance is the complete omission of CNIs from the de novo maintenance immunosuppression regimen, whereas CNI minimization uses reduced doses of CNIs to limit their nephrotoxicity. CNI-free protocols do not show improvement in graft outcomes. The ELITE-Symphony study is a randomized prospective trial that compared CNI avoidance and minimization strategies by randomizing recipients to 1 of 4 groups: low-dose SRL, lowdose TAC, low-dose CsA, or standard-dose CsA [71]. Renal allograft function was better and biopsy-proven AR rates were significantly lower in the low-dose TAC group than all other treatment groups. Furthermore, allograft survival was better with low-dose TAC compared to standard-dose CsA and low-dose SRL. CNI avoidance with low-dose SRL failed to show improvement in renal function, and the biopsy-proven AR rate and graft survival were significantly worse than low-dose TAC. Many other trials have also shown that CNI avoidance protocols did not confer a benefit in GFR or allograft histology in patients treated with SRL $[72,73]$. In a prospective and randomized trial of complete avoidance of CNIs, Larson et al. [72] compared a group of kidney transplant recipients who received SRL-MMF-prednisone (81 patients) to a group of patients who received TAC-MMF-prednisone (83 patients) as maintenance immunosuppression with a mean follow-up of 33 months. The 1-year patient and graft survival was similar in both groups $(\mathrm{p}=0.95)$. There was also no difference in iothalamate GFR between the TAC and SRL groups at 1 and 2 years. Interestingly, there was no difference in interstitial, tubular, or glomerular changes at 1 year by the Banff chronicity criteria scoring. 
Table 1. Different CNI-sparing prospective clinical trials

\begin{tabular}{|c|c|c|c|c|c|c|}
\hline Study & Comparison groups & Patients, $\mathrm{n}$ & $\begin{array}{l}\text { Follow-up } \\
\text { months }\end{array}$ & $\begin{array}{l}\text { Incidence } \\
\text { of } A R\end{array}$ & Graft function & $\begin{array}{l}\text { Graft } \\
\text { survival }\end{array}$ \\
\hline \multicolumn{7}{|l|}{ CNI avoidance protocols } \\
\hline Larson et al. [72] & $\begin{array}{l}\text { TAC-MMF-pred vs. } \\
\text { SRL-MMF-pred }\end{array}$ & 165 & 33 & similar & similar & similar \\
\hline $\begin{array}{l}\text { Flechner et al. [74] } \\
\text { (ORION) }\end{array}$ & $\begin{array}{l}\text { SRL-TAC (elimination } \\
\text { at } 13 \text { weeks)-pred vs. } \\
\text { SRL-MMF-pred }{ }^{1} \text { vs. } \\
\text { TAC-MMF-pred }\end{array}$ & 443 & 24 & $\begin{array}{l}\uparrow \text { SRL-MMF- } \\
\text { pred }\end{array}$ & similar & similar \\
\hline $\begin{array}{l}\text { Durrbach et al. [78] } \\
\text { (BENEFIT-EXT) }\end{array}$ & $\begin{array}{l}\text { belatacept (more intensive)- } \\
\text { MMF-pred vs. belatacept } \\
\text { (less intensive)-MMF-pred vs. } \\
\text { CsA-MMF-pred (ECD) }\end{array}$ & 543 & 12 & similar & $\begin{array}{l}\uparrow \text { belatacept (more } \\
\text { and less intensive)- } \\
\text { MMF-pred }\end{array}$ & similar \\
\hline $\begin{array}{l}\text { CNI elimination protoc } \\
\text { Lebranchu et al. [79] } \\
\text { (CONCEPT) }\end{array}$ & $\begin{array}{l}\text { cols - conversion to SRL-based re } \\
\text { CsA-MMF-pred vs. } \\
\text { SRL-MMF-pred }\end{array}$ & $\begin{array}{r}\text { gimen } \\
193\end{array}$ & 13 & similar & $\uparrow$ SRL-MMF-pred & similar \\
\hline $\begin{array}{l}\text { Weir et al. [80] } \\
\text { (Spare-the-Nephron) }\end{array}$ & $\begin{array}{l}\text { CsA or TAC-MMF vs. } \\
\text { SRL-MMF }\end{array}$ & 299 & 24 & similar & $\uparrow \mathrm{SRL}-\mathrm{MMF}$ & similar \\
\hline
\end{tabular}

$\mathrm{AZA}=$ Azathioprine; $\mathrm{DAC}=$ daculizumab induction; $\mathrm{ECD}=$ extended criteria donors; pred $=$ prednisone. ${ }^{1}$ Study arm terminated early for higher than expected AR rates.

In the Orion Study, Flechner et al. [74] randomized patients to 3 groups: SRL-TAC followed by TAC elimination at 13 weeks, SRL-MMF, and TAC-MMF. The SRLMMF group had high biopsy-proven AR and was terminated early by the sponsor. The SRL-based regimens were associated with poorer outcomes in kidney transplant recipients.

It is important to note that the small single-center experiences reported by Larson et al. [72] and Flechner et al. [74] recruited patients with relatively low immunological risk in centers that were experienced in the use of SRL and MMF. A greater problem with external validity appears when one examines CNI-free regimens using registry data where the population differs from initial experiences. When CNI-free regimens are used in the context of the larger US population, rejection rates and tolerability were poor and CNIs containing regimens fared better [75]. Using the Scientific Registry of Renal Transplant Recipients, Srinivas et al. [75] showed that allograft survival in deceased donor transplants was significantly lower with SRL/MMF compared to patients on TAC/MMF or CsA/ MMF regimens at 5 years posttransplant $(64,78$, and $78 \%$, respectively, $\mathrm{p}=0.001$ ) and across all patient subgroups.

Another randomized trial showed that conversion from TAC to SRL at 1 month posttransplant in kidney transplant recipients on a rapid steroid withdrawal protocol 
does not halt or improve the progression of chronic changes on protocol biopsies during the first 2 years even in those patients without previous AR [76]. More recently, novel immunosuppressant agents such as belatacept (a T cell costimulation blocker) were studied as alternatives to CNIs. In fact, belatacept was approved as an immunosuppressant for Epstein-Barr virus-positive adult kidney transplant recipients and is to be used concomitantly with MMF and prednisone. Two trials compared belatacept with CsA: the BENEFIT trial in recipients of standard criteria living kidney donors [77] and the BENEFIT-EXT [78] in recipients of extended criteria deceased kidney donors. In the BENEFIT trial, belatacept had similar patient and graft survival rates compared with CsA at 1 year posttransplant. Moreover, belatacept-treated patients had higher measured GFRs. Despite the higher incidence of early AR in the belatacept group, biopsy-proven chronic allograft changes were minimally reduced in the belatacept groups and at 5 years there was no difference in chronic allograft nephropathy (per belatacept package insert). Belatacept is associated with a higher incidence of posttransplant lymphoproliferative disorder involving the central nervous system in Epstein-Barr virus-negative patients. Similar outcomes were reported in the BENFIT-EXT study.

\section{CNI Elimination Protocols}

CNI elimination involves the complete withdrawal of CNIs from transplant recipients who had been initially placed on CNIs. CNI withdrawal and replacement with SRL was evaluated by many trials with mixed reported results. The main trials were the CONCEPT study [79], Spare-the-Nephron trial [80], and the CONVERT trial [81]. There was better renal allograft function in the CNI withdrawal group in the CONCEPT study in contrast to the Spare-the-Nephron and CONVERT trials, which did not show significant improvement in renal allograft function after conversion to SRL 2 years after transplantation. However, late CNI withdrawal in the CONCEPT trial was actually harmful to recipients with proteinuria. The postCONCEPT study showed that the results of the conversion from CsA to SRL at 3 months posttransplantation of the CONCEPT study were maintained [82]. However, there was more proteinuria and new-onset diabetes mellitus with SRL use. In the CONVERT trial, late CNI withdrawal showed no significant differences in primary safety outcomes. In fact, enrollment in the GFR 20-40 ml/ min group was halted prematurely due to a higher incidence of safety endpoints among the SRL conversion patients. The CAESAR trial [33] evaluated CNI minimization and withdrawal strategies by randomizing patients to low-dose CsA, low-dose CsA with early withdrawal, and standard-dose CsA. Renal allograft function was similar in all 3 groups. However, the biopsy-proven AR rate was higher in the CsA withdrawal group but not in the lowdose CsA group, adding more evidence about exercising caution even with early elimination of CNIs. It is worth noting that most of the CNI-sparing studies had relatively short-term follow-up and more importantly lacked protocol biopsies; therefore, quantitation of CNI histological toxicity remains elusive (particularly as it pertains to the long term).

CNIs remain the backbone of current immunosuppression and have been associated with excellent graft survival rates despite the shifting patterns in immunosuppressive regimens (including steroid avoidance and CNIsparing protocols) and the use of higher-risk kidney donors. Despite the association with nephrotoxicity, CNIs did not adversely affect changes in renal function after transplantation in the US population, as large registry data show that slopes and intercepts of GFRs are not different and were not impacted by the type of immunosuppression [83]. GFR slopes and intercepts and 1-year survival rates have improved in the United States independently of donor quality and immunosuppressive regimen [83].

\section{New Evidence Revealed: Alloimmunity Is the Major Cause of Late Allograft Failure and Not CNI Use}

Over the past 3 decades, the transplant community focused research efforts and immunosuppressive strategies in solid organ transplantation on $\mathrm{T}$ cell depletion and neglected the role of B cells, plasma cells, and HLA antibodies. Antibody-mediated rejection was originally recognized by the presence of donor-specific antibodies and microcirculation injury [84]. Iványi et al. [85] described microcirculatory changes in peritubular capillaries and basement membrane multilayering as a marker of chronic renal allograft rejection. Later on, with the advent of new tools for alloantibody detection, antibody-mediated rejection was increasingly recognized as one of the main challenges in organ transplantation and a hurdle to longterm allograft survival. It was then shown that the appearance of de novo donor-specific antibodies and the development of acute antibody-mediated rejection negatively impact allograft survival [86]. Antibody-mediated rejection is currently defined by deposition of complement factor C4d in peritubular capillaries [87]. Over time, transplant glomerulopathy develops due to chronic antibody-mediated injury and thereby causes late allograft 
failure $[88,89]$. However, it is now evident that $\mathrm{C} 4 \mathrm{~d}$ is not a sensitive marker and there is growing evidence of the presence of C4d-negative antibody-mediated injury [90].

It is increasingly clear that most of the chronic changes that have been attributed to chronic CNI nephrotoxicity in kidney transplant recipients are actually the consequence of previously unrecognized immunologic injury. The DeKAF study was a multicenter study that enrolled patients with new-onset late graft dysfunction and who underwent kidney transplant biopsy (mean time from transplant: $7.5 \pm 6$ years) [91]. Data from the DeKAF study on the etiology of late allograft loss show that about $57 \%$ of patients with chronic graft dysfunction have, in reality, underlying antibody-mediated injury [91]. Moreover, other groups have shown that the major etiology of late kidney transplant failure is antibody-mediated microcirculation injury $[88,92]$. This has been highlighted in a landmark study by El-Zoghby et al. [93] who showed that almost all cases of kidney allograft loss have an identifiable cause that is not idiopathic interstitial fibrosis/tubular atrophy or CNI nephrotoxicity, and that alloimmunity is the main mechanism leading to allograft failure. Hill et al. [94] reported donor-specific anti-HLA antibodies dramatically accelerate posttransplant progression of arteriosclerosis and that the histologic lesions most referred to as related to CNI chronic nephrotoxicity are mainly related to chronic antibody-mediated rejection by employing protocol biopsies. Stegall et al. [95] reported that moderate-to-severe arteriolar hyalinosis, which has been described as the hallmark of chronic CNI nephrotoxicity, was found to a similar extent in kidney transplant recipients who were never exposed to CNIs compared to patients treated with CNIs using protocol biopsies at 5 years posttransplantation. Sellarés et al. [96] studied prospectively 315 kidney recipients who underwent indication biopsies at 6 days to 32 years posttransplant and who progressed to failure, with the aim of assigning a cause to every failure. Sixty kidneys progressed to failure during the median follow-up period of 31.4 months. Failure was rare after T cell-mediated rejection and common after antibody-mediated rejection or glomerulonephritis. Nonadherence was more frequent in patients who progressed to failure $(32 \%)$ versus those whose allografts survived (3\%). Pure T cell-mediated rejection, CNI toxicity, and unexplained progressive fibrosis were not causes of graft loss. An interesting recent study by Famulski et al. [97] shed light on the role of acute kidney injury transcripts in late allograft loss and nontoxic drug effects. In multivariate survival analysis, they found that the injury signal in late kidney transplant bi- opsies strongly predicted future graft loss. They concluded that progression in troubled transplants is primarily a function of ongoing parenchymal injury by disease (antibody-mediated injury or glomerulonephritis) and not fibrogenesis caused by CNIs.

Taken together, these recent studies suggest that the observed progression of chronic kidney allograft damage is more the result of subclinical alloimmune injury than just exposure to CNIs.

\section{Conclusion}

Late renal allograft failure remains a major problem in kidney transplantation. CNI nephrotoxicity has been highly overexaggerated as a cause of chronic allograft dysfunction and loss. Early clinical experience and animal studies support the evidence of CNI nephrotoxicity; however, in transplanted kidneys the specific role of chronic CNI nephrotoxicity has yet to be defined. To date, it can be concluded that while there is no doubt CNIs are nephrotoxic agents, there is no hard and tangible evidence that systemic exposure to CNIs represents the major determinant of the risk for chronic allograft failure. A growing body of evidence shows that alloimmunity is the major mechanism leading to late renal allograft failure, and contrary to common beliefs those graft losses are not always attributable to CNI use. In fact, CNI-based immunosuppression regimens remain the proven standard in kidney transplantation. Chronic CNI-induced nephrotoxicity remains controversial due to the lack of solid evidence of their injurious role and the nonspecificity of the pathological lesions that have been traditionally linked to their use. This makes the differential diagnosis with other immunological and nonimmunological processes very cumbersome. Whether lower CNI systemic exposure in de novo renal transplantation leads to lower incidence or slower progression of chronic allograft failure needs to be tested in large prospective randomized clinical trials, which should include subclinical histologic examination of the allografts as a surrogate endpoint.

\section{Disclosure Statement}

The authors have no conflicts of interest to disclose. 


\section{References}

$>1$ Lamb KE, Lodhi S, Meier-Kriesche HU: 16 Bobadilla NA, Gamba G: New insights into Long-term renal allograft survival in the United States: a critical reappraisal. Am J Transplant 2011;11:450-462.

2 Nankivell BJ, Borrows RJ, Fung CL, O’Connell PJ, Allen RD, Chapman JR: The natural history of chronic allograft nephropathy. N Engl J Med 2003;349:2326-2333.

-3 Takahashi N, Hayano T, Suzuki M: Peptidylprolyl cis-trans isomerase is the cyclosporin A-binding protein cyclophilin. Nature 1989; 337:473-475.

4 Harding MW, Galat A, Uehling DE, Schreiber SL: A receptor for the immunosuppressant FK506 is a cis-trans peptidyl-prolyl isomerase. Nature 1989;341:758-760.

$\checkmark 5$ Fischer G, Wittmann-Liebold B, Lang K, Kiefhaber T, Schmid FX: Cyclophilin and peptidyl-prolyl cis-trans isomerase are probably identical proteins. Nature 1989;337:476478.

6 Jain J, McCaffrey PG, Miner Z, Kerppola TK, Lambert JN, Verdine GL, et al: The T-cell transcription factor NFATp is a substrate for calcineurin and interacts with Fos and Jun. Nature 1993;365:352-355.

7 Flanagan WM, Corthesy B, Bram RJ, Crabtree GR: Nuclear association of a T-cell transcription factor blocked by FK-506 and cyclosporin A. Nature 1991;352:803-807.

$>8$ Macian F: NFAT proteins: key regulators of T-cell development and function. Nat Rev Immunol 2005;5:472-484.

-9 Clipstone NA, Crabtree GR: Identification of calcineurin as a key signalling enzyme in Tlymphocyte activation. Nature 1992;357:695697.

$>10$ O’Keefe SJ, Tamura J, Kincaid RL, Tocci MJ, O'Neill EA: FK-506- and CsA-sensitive activation of the interleukin-2 promoter by calcineurin. Nature 1992;357:692-694.

$>11$ Kung L, Batiuk TD, Palomo-Pinon S, Noujaim J, Helms LM, Halloran PF: Tissue distribution of calcineurin and its sensitivity to inhibition by cyclosporine. Am J Transplant 2001;1:325-333.

-12 Halloran PF, Helms LM, Kung L, Noujaim J: The temporal profile of calcineurin inhibition by cyclosporine in vivo. Transplantation 1999;68:1356-1361.

$>13$ Sollinger HW: Mycophenolate mofetil for the prevention of acute rejection in primary cadaveric renal allograft recipients. U.S. Renal Transplant Mycophenolate Mofetil Study Group. Transplantation 1995;60:225-232.

14 English J, Evan A, Houghton DC, Bennett WM: Cyclosporine-induced acute renal dysfunction in the rat. Evidence of arteriolar vasoconstriction with preservation of tubular function. Transplantation 1987;44:135-141.

-15 Laskow DA, Curtis JJ, Luke RG, Julian BA, Jones P, Deierhoi MH, et al: Cyclosporine-induced changes in glomerular filtration rate and urea excretion. Am J Med 1990;88:497502 . the pathophysiology of cyclosporine nephrotoxicity: a role of aldosterone. Am J Physiol Renal Physiol 2007;293:F2-F9.

17 Burdmann EA, Andoh TF, Yu L, Bennett WM: Cyclosporine nephrotoxicity. Semin Nephrol 2003;23:465-476.

-18 Kon V, Sugiura M, Inagami T, Harvie BR, Ichikawa I, Hoover RL: Role of endothelin in cyclosporine-induced glomerular dysfunction. Kidney Int 1990;37:1487-1491.

$>19$ Textor SC, Burnett JC Jr, Romero JC, Canzanello VJ, Taler SJ, Wiesner R, et al: Urinary endothelin and renal vasoconstriction with cyclosporine or FK506 after liver transplantation. Kidney Int 1995;47:1426-1433.

20 Hocherl K, Dreher F, Vitzthum H, Kohler J, Kurtz A: Cyclosporine A suppresses cyclooxygenase-2 expression in the rat kidney. J Am Soc Nephrol 2002;13:2427-2436.

21 Hocherl K, Kees F, Kramer BK, Kurtz A: Cyclosporine $\mathrm{A}$ attenuates the natriuretic action of loop diuretics by inhibition of renal COX-2 expression. Kidney Int 2004;65:2071-2080.

22 Andoh TF, Bennett WM: Chronic cyclosporine nephrotoxicity. Curr Opin Nephrol Hypertens 1998;7:265-270.

23 Mihatsch MJ, Kyo M, Morozumi K, Yamaguchi Y, Nickeleit V, Ryffel B: The side-effects of ciclosporine-A and tacrolimus. Clin Nephrol

24 Kershner RP, Fitzsimmons WE: Relationship of FK506 whole blood concentrations and efficacy and toxicity after liver and kidney transplantation. Transplantation 1996;62: 920-926.

25 Lemahieu W, Maes B, Verbeke K, Rutgeerts P, Geboes K, Vanrenterghem Y: Cytochrome P450 3A4 and P-glycoprotein activity and assimilation of tacrolimus in transplant patients with persistent diarrhea. Am J Transplant 2005;5:1383-1391.

26 International Neoral Renal Transplantation Study Group. Cyclosporine microemulsion (Neoral) absorption profiling and sparsesample predictors during the first 3 months after renal transplantation. Am J Transplant 2002;2:148-156.

-27 Knight SR, Morris PJ: The clinical benefits of cyclosporine C2-level monitoring: a systematic review. Transplantation 2007;83:15251535 .

28 Nankivell BJ, Borrows RJ, Fung CL, O’Connell PJ, Chapman JR, Allen RD: Calcineurin inhibitor nephrotoxicity: longitudinal assessment by protocol histology. Transplantation 2004;78:557-565.

29 Naesens M, Lerut E, Damme BV, Vanrenterghem Y, Kuypers DR: Tacrolimus exposure and evolution of renal allograft histology in the first year after transplantation. Am J Transplant 2007;7:2114-2123. 1998;49:356-363.
30 Seron D, Moreso F, Fulladosa X, Hueso M, Carrera M, Grinyo JM: Reliability of chronic allograft nephropathy diagnosis in sequential protocol biopsies. Kidney Int 2002;61:727-733.

31 Ekberg H, Bernasconi C, Noldeke J, Yussim A, Mjornstedt L, Erken U, et al: Cyclosporine, tacrolimus and sirolimus retain their distinct toxicity profiles despite low doses in the Symphony study. Nephrol Dial Transplant 2010; 25:2004-2010.

-32 Shihab FS, Waid TH, Conti DJ, Yang H, Holman MJ, Mulloy LC, et al: Conversion from cyclosporine to tacrolimus in patients at risk for chronic renal allograft failure: 60-month results of the CRAF Study. Transplantation 2008;85:1261-1269.

33 Ekberg H, Grinyo J, Nashan B, Vanrenterghem Y, Vincenti F, Voulgari A, et al: Cyclosporine sparing with mycophenolate mofetil, daclizumab and corticosteroids in renal allograft recipients: the CAESAR Study. Am J Transplant 2007;7:560-570.

34 Hesselink DA, Bouamar R, van Gelder T: The pharmacogenetics of calcineurin inhibitorrelated nephrotoxicity. Ther Drug Monit 2010;32:387-393.

35 Naesens M, Lerut E, de Jonge H, Van Damme B, Vanrenterghem Y, Kuypers DR: Donor age and renal P-glycoprotein expression associate with chronic histological damage in renal allografts. J Am Soc Nephrol 2009;20:2468-2480.

36 Joy MS, Hogan SL, Thompson BD, Finn WF, Nickeleit V: Cytochrome P450 3A5 expression in the kidneys of patients with calcineurin inhibitor nephrotoxicity. Nephrol Dial Transplant 2007;22:1963-1968.

37 Bandur S, Petrasek J, Hribova P, Novotna E, Brabcova I, Viklicky O: Haplotypic structure of $\mathrm{ABCB} 1 / \mathrm{MDR} 1$ gene modifies the risk of the acute allograft rejection in renal transplant recipients. Transplantation 2008;86: 1206-1213.

38 Quteineh L, Verstuyft C, Furlan V, Durrbach $A$, Letierce A, Ferlicot S, et al: Influence of CYP3A5 genetic polymorphism on tacrolimus daily dose requirements and acute rejection in renal graft recipients. Basic Clin Pharmacol Toxicol 2008;103:546-552.

39 Naesens M, Kuypers DR, Sarwal M: Calcineurin inhibitor nephrotoxicity. Clin J Am Soc Nephrol 2009;4:481-508.

$\checkmark 40$ Djamali A, Reese S, Hafez O, Vidyasagar A, Jacobson L, Swain W, et al: Nox2 is a mediator of chronic CsA nephrotoxicity. Am J Transplant 2012;12:1997-2007.

41 Elzinga LW, Rosen S, Burdmann EA, Hatton DC, Lindsley J, Bennett WM: The role of renal sympathetic nerves in experimental chronic cyclosporine nephropathy. Transplantation 2000;69:2149-153.

42 Hausberg M, Lang D, Levers A, Suwelack B, Kisters K, Tokmak F, et al: Sympathetic nerve activity in renal transplant patients before and after withdrawal of cyclosporine. J Hypertens 2006;24:957-964. 
-43 Myers BD, Ross J, Newton L, Luetscher J, Perlroth M: Cyclosporine-associated chronic nephropathy. N Engl J Med 1984;311:699705.

-44 Ojo AO, Held PJ, Port FK, Wolfe RA, Leichtman AB, Young EW, et al: Chronic renal failure after transplantation of a nonrenal organ. N Engl J Med 2003;349:931-940.

-45 Soin AS, Rasmussen A, Jamieson NV, Watson CJ, Friend PJ, Wight DG, et al: CsA levels in the early posttransplant period - predictive of chronic rejection in liver transplantation? Transplantation 1995;59:1119-1123.

- 46 Yoshida EM, Marotta PJ, Greig PD, Kneteman NM, Marleau D, Cantarovich M, et al: Evaluation of renal function in liver transplant recipients receiving daclizumab (Zenapax), mycophenolate mofetil, and a delayed, low-dose tacrolimus regimen vs. a standarddose tacrolimus and mycophenolate mofetil regimen: a multicenter randomized clinical trial. Liver Transpl 2005;11:1064-1072.

- 47 McGuire BM, Julian BA, Bynon JS Jr, Cook WJ, King SJ, Curtis JJ, et al: Brief communication: glomerulonephritis in patients with hepatitis $\mathrm{C}$ cirrhosis undergoing liver transplantation. Ann Intern Med 2006;144:735-741.

48 Bloom RD, Reese PP: Chronic kidney disease after nonrenal solid-organ transplantation. J Am Soc Nephrol 2007;18:3031-3041.

-49 Canales M, Youssef P, Spong R, Ishani A, Savik K, Hertz M, et al: Predictors of chronic kidney disease in long-term survivors of lung and heart-lung transplantation. Am J Transplant 2006;6:2157-2163.

-50 Hamour IM, Omar F, Lyster HS, Palmer A, Banner NR: Chronic kidney disease after heart transplantation. Nephrol Dial Transplant 2009;24:1655-1662.

-51 O'Riordan A, Dutt N, Cairns H, Rela M, O'Grady JG, Heaton N, et al: Renal biopsy in liver transplant recipients. Nephrol Dial Transplant 2009;24:2276-2282.

52 Kim JY, Akalin E, Dikman S, Gagliardi R, Schiano T, Bromberg J, et al: The variable pathology of kidney disease after liver transplantation. Transplantation 2010;89:215-221.

-53 Young EW, Ellis CN, Messana JM, Johnson KJ, Leichtman AB, Mihatsch MJ, et al: A prospective study of renal structure and function in psoriasis patients treated with cyclosporin. Kidney Int 1994;46:1216-1222.

-54 Isnard Bagnis C, Tezenas du Montcel S, Beaufils H, Jouanneau C, Jaudon MC, Maksud P, et al: Long-term renal effects of low-dose cyclosporine in uveitis-treated patients: follow-up study. J Am Soc Nephrol 2002;13:2962-2968.

-55 Pei Y, Scholey JW, Katz A, Schachter R, Murphy GF, Cattran D: Chronic nephrotoxicity in psoriatic patients treated with low-dose cyclosporine. Am J Kidney Dis 1994;23:528536.
Mihatsch MJ, Thiel G, Basler V, Ryffel B, Landmann J, von Overbeck J, et al: Morphological patterns in cyclosporine-treated renal transplant recipients. Transplant Proc 1985; 17:101-116.

57 Nankivell BJ, Wavamunno MD, Borrows RJ, Vitalone M, Fung CL, Allen RD, et al: Mycophenolate mofetil is associated with altered expression of chronic renal transplant histology. Am J Transplant 2007;7:366-376.

58 Mazur MJ, Rea DJ, Griffin MD, Larson TS, Prieto M, Gloor JM, et al: Decline in native renal function early after bladder-drained pancreas transplantation alone. Transplantation 2004;77:844-849.

59 Snanoudj R, Royal V, Elie C, Rabant M, Girardin C, Morelon E, et al: Specificity of histological markers of long-term CNI nephrotoxicity in kidney-transplant recipients under low-dose cyclosporine therapy. Am J Transplant 2011;11:2635-2646.

60 Mengel M, Mihatsch M, Halloran PF: Histological characteristics of calcineurin inhibitor toxicity - there is no such thing as specificity! Am J Transplant 2011;11:2549-2550.

61 Nankivell BJ, Chapman JR: Chronic allograft nephropathy: current concepts and future directions. Transplantation 2006;81:643-654.

62 Randhawa P, Ho A, Shapiro R, Vats A, Swalsky $\mathrm{P}$, Finkelstein $\mathrm{S}$, et al: Correlates of quantitative measurement of $\mathrm{BK}$ polyomavirus (BKV) DNA with clinical course of BKV infection in renal transplant patients. J Clin $\mathrm{Mi}$ crobiol 2004;42:1176-1180.

-63 Buehrig CK, Lager DJ, Stegall MD, Kreps MA, Kremers WK, Gloor JM, et al: Influence of surveillance renal allograft biopsy on diagnosis and prognosis of polyomavirus-associated nephropathy. Kidney Int 2003;64:665-673.

64 Hirsch HH: Polyomavirus BK nephropathy: a (re-)emerging complication in renal transplantation. Am J Transplant 2002;2:25-30.

65 Kahan BD: Efficacy of sirolimus compared with azathioprine for reduction of acute renal allograft rejection: a randomised multicentre study. The Rapamune US Study Group. Lancet 2000;356:194-202.

66 Halloran PF: Sirolimus and cyclosporin for renal transplantation. Lancet 2000;356:179180.

67 Andoh TF, Lindsley J, Franceschini N, Bennett WM: Synergistic effects of cyclosporine and rapamycin in a chronic nephrotoxicity model. Transplantation 1996;62:311-316.

68 Ciancio G, Burke GW, Gaynor JJ, Ruiz P, Roth $\mathrm{D}$, Kupin W, et al: A randomized long-term trial of tacrolimus/sirolimus versus tacrolimus/mycophenolate versus cyclosporine/sirolimus in renal transplantation: three-year analysis. Transplantation 2006;81:845-852.

69 Meier-Kriesche HU, Schold JD, Srinivas TR, Howard RJ, Fujita S, Kaplan B: Sirolimus in combination with tacrolimus is associated with worse renal allograft survival compared to mycophenolate mofetil combined with tacrolimus. Am J Transplant 2005;5:22732280.
70 Mendez R, Gonwa T, Yang HC, Weinstein S, Jensik S, Steinberg S, et al: A prospective, randomized trial of tacrolimus in combination with sirolimus or mycophenolate mofetil in kidney transplantation: results at 1 year. Transplantation 2005;80:303-309.

71 Ekberg H, Tedesco-Silva H, Demirbas A, Vitko S, Nashan B, Gurkan A, et al: Reduced exposure to calcineurin inhibitors in renal transplantation. N Engl J Med 2007;357: 2562-2575.

72 Larson TS, Dean PG, Stegall MD, Griffin MD, Textor SC, Schwab TR, et al: Complete avoidance of calcineurin inhibitors in renal transplantation: a randomized trial comparing sirolimus and tacrolimus. Am J Transplant 2006;6:514-522.

73 Dean PG, Grande JP, Sethi S, Park WD, Griffin MD, Cosio FG, et al: Kidney transplant histology after one year of continuous therapy with sirolimus compared with tacrolimus. Transplantation 2008;85:1212-1215.

74 Flechner SM, Glyda M, Cockfield S, Grinyo J, Legendre C, Russ G, et al: The ORION study: comparison of two sirolimus-based regimens versus tacrolimus and mycophenolate mofetil in renal allograft recipients. Am J Transplant 2011;11:1633-1644.

75 Srinivas TR, Schold JD, Guerra G, Eagan A, Bucci CM, Meier-Kriesche HU: Mycophenolate mofetil/sirolimus compared to other common immunosuppressive regimens in kidney transplantation. Am J Transplant 2007;7:586-594.

76 Heilman RL, Cortese C, Geiger XJ, Younan K, Wadei HM, Mai ML, et al: Impact of early conversion from tacrolimus to sirolimus on chronic allograft changes in kidney recipients on rapid steroid withdrawal. Transplantation 2012;93:47-53.

77 Vincenti F, Charpentier B, Vanrenterghem Y, Rostaing L, Bresnahan B, Darji P, et al: A phase III study of belatacept-based immunosuppression regimens versus cyclosporine in renal transplant recipients (BENEFIT study). Am J Transplant 2010;10:535-546.

78 Durrbach A, Pestana JM, Pearson T, Vincenti F, Garcia VD, Campistol J, et al: A phase III study of belatacept versus cyclosporine in kidney transplants from extended criteria donors (BENEFIT-EXT study). Am J Transplant 2010;10:547-557.

79 Lebranchu Y, Thierry A, Toupance O, Westeel PF, Etienne I, Thervet E, et al: Efficacy on renal function of early conversion from cyclosporine to sirolimus 3 months after renal transplantation: CONCEPT study. Am J Transplant 2009;9:1115-1123.

80 Weir MR, Mulgaonkar S, Chan L, Shidban H, Waid TH, Preston D, et al: Mycophenolate mofetil-based immunosuppression with sirolimus in renal transplantation: a randomized, controlled Spare-the-Nephron trial. Kidney Int 2011;79:897-907. 
-81 Schena FP, Pascoe MD, Alberu J, del Carmen Rial M, Oberbauer R, Brennan DC, et al: Conversion from calcineurin inhibitors to sirolimus maintenance therapy in renal allograft recipients: 24 -month efficacy and safety results from the CONVERT trial. Transplantation 2009;87:233-242.

82 Lebranchu Y, Thierry A, Thervet E, Buchler M, Etienne I, Westeel PF, et al: Efficacy and safety of early cyclosporine conversion to sirolimus with continued MMF-four-year results of the Postconcept study. Am J Transplant 2011;11:1665-1675.

-83 Srinivas TR, Flechner SM, Poggio ED, Askar M, Goldfarb DA, Navaneethan SD, et al: Glomerular filtration rate slopes have significantly improved among renal transplants in the United States. Transplantation 2010;90: 1499-1505.

84 Halloran PF, Wadgymar A, Ritchie S, Falk J, Solez K, Srinivasa NS: The significance of the anti-class I antibody response. I. Clinical and pathologic features of anti-class I-mediated rejection. Transplantation 1990;49:85-91.

85 Iványi B, Fahmy H, Brown H, Szenohradszky P, Halloran PF, Solez K: Peritubular capillaries in chronic renal allograft rejection: a quantitative ultrastructural study. Hum Pathol 2000;31:1129-1138.
86 Mao Q, Terasaki PI, Cai J, Briley K, Catrou P, Haisch C, et al: Extremely high association between appearance of HLA antibodies and failure of kidney grafts in a five-year longitudinal study. Am J Transplant 2007;7:864-871.

87 Racusen LC, Halloran PF, Solez K: Banff 2003 meeting report: new diagnostic insights and standards. Am J Transplant 2004;4:15621566.

88 Issa N, Cosio FG, Gloor JM, Sethi S, Dean PG, Moore SB, et al: Transplant glomerulopathy: risk and prognosis related to anti-human leukocyte antigen class II antibody levels. Transplantation 2008;86:681-685.

89 Sis B, Campbell PM, Mueller T, Hunter C, Cockfield SM, Cruz J, et al: Transplant glomerulopathy, late antibody-mediated rejection and the $A B C D$ tetrad in kidney allograft biopsies for cause. Am J Transplant 2007;7: 1743-1752.

90 Solez K, Colvin RB, Racusen LC, Haas M, Sis $\mathrm{B}$, Mengel M, et al: Banff 07 classification of renal allograft pathology: updates and future directions. Am J Transplant 2008;8: 753-760.

91 Gaston RS, Cecka JM, Kasiske BL, Fieberg AM, Leduc R, Cosio FC, et al: Evidence for antibody-mediated injury as a major determinant of late kidney allograft failure. Transplantation 2010;90:68-74.
92 Einecke G, Sis B, Reeve J, Mengel M, Campbell PM, Hidalgo LG, et al: Antibody-mediated microcirculation injury is the major cause of late kidney transplant failure. Am J Transplant 2009;9:2520-2531.

93 El-Zoghby ZM, Stegall MD, Lager DJ, Kremers WK, Amer H, Gloor JM, et al: Identifying specific causes of kidney allograft loss. Am J Transplant 2009;9:527-535.

94 Hill GS, Nochy D, Bruneval P, Duong van Huyen JP, Glotz D, Suberbielle C, et al: Donor-specific antibodies accelerate arteriosclerosis after kidney transplantation. J Am Soc Nephrol 2011;22:975-983.

$\$ 95$ Stegall MD, Park WD, Larson TS, Gloor JM Cornell LD, Sethi S et al. The histology of solitary renal allografts at 1 and 5 years after transplantation. Am J Transplant 2011;11: 698-707.

-96 Sellarés J, de Freitas DG, Mengel M, Reeve J, Einecke G, Sis B, et al: Understanding the causes of kidney transplant failure: the dominant role of antibody-mediated rejection and nonadherence. Am J Transplant 2012;12: 388-399.

97 Famulski KS, Reeve J, de Freitas DG, Kreepala C, Chang J, Halloran PF: Kidney transplants with progressing chronic diseases express high levels of acute kidney injury transcripts. Am J Transplant 2013;13:634-644. 